\title{
'PARTICULARIDADES' HISTÓRICAS MEXICANAS: BREVE RECUENTO
}

Javier Garciadiego*

A mi inolvidable amigo Carlos Márquez Padilla. ¡Cómo me gustaría discutir este artículo con él, y no simplemente dedicárselo!

Sin excepción alguna, todos los países tienen una historia 'excepcional'. Por lo tanto, sus 'excepcionalidades' no son verdaderas excepciones. Es más, también sus componentes regionales y locales tienen sus propias historias 'excepcionales', lo que hace de toda historia nacional una suma de supuestas 'excepcionalidades'. A riesgo de diluir cualquier potencialidad cognoscitiva que pudiera tener este concepto, debe afirmarse que la 'excepcionalidad' nunca es total sino que coexiste con muchos elementos comunes, compartidos tanto por países como por regiones y localidades. Acaso sería menos riesgoso utilizar el término 'particularidades', aunque habría que insistir en que este concepto no es sinónimo de 'exclusividades'. Obviamente, 'particularidad' tampoco es sinónimo de virtud no compartida, de virtud única. Sería absurdo suponer que las 'particularidades' que puedan caracterizar la historia mexicana impliquen

* El Colegio de México. Agradezco el apoyo de Ma. del Rayo González Vázquez, así como los comentarios de mis colegas Marco T. Águila, Alberto Arnaut, Mónica Blanco, Gabriela Cano, Georgette José, Marta Loyo, Antonio Saborit, Alicia Salmerón y Pablo Yankelevich. 
superioridad alguna, y mucho menos un necio afán de excentricidad. No es un asunto de vanidad chovinista: sus 'particularidades', en caso de ser auténticas, son sólo eso: 'particularidades'.

La primera radica en que sus orígenes más remotos son tan antiguos, y de tal envergadura, que puede asegurarse que México tenía otra historia antes siquiera de comenzar la más propiamente suya. En efecto, en el territorio que hoy se conoce como México habían vivido durante siglos varios pueblos que compartían numerosos elementos étnicos y culturales, a pesar de sus grandes diferencias lingüísticas y políticas. El lapso temporal de su existencia era tal, que para principios de nuestro siglo XVI algunos de ellos tenían entre un milenio y cinco centurias de haberse extinguido o de haber entrado en irreversibles procesos de decadencia. ${ }^{2}$ El más joven de todos estos pueblos, el azteca o mexica, constituyó con sus vecinos -inmediatos, cercanos y hasta distantes- un conglomerado político, económico, cultural y militar cuya articulación ha merecido que se le llame Imperio. ${ }^{3} \mathrm{Si}$ bien en la región andina existieron pueblos indígenas con una historia igualmente longeva, allí no hubo un proceso de integración estatal como el habido en los territorios vinculados a los aztecas. ${ }^{4}$

La segunda 'particularidad' es que a diferencia de los pueblos nativos de las islas del Caribe, que fueron exterminados por sus descu-

${ }^{1}$ Según el Diccionario de la Lengua Española, de la Real Academia Española, lo 'excepcional' se aparta de lo común u ocurre rara vez, y 'particular' significa 'especial, extraordinario, o pocas veces visto'. En cualquier diccionario especializado se consignan como sinónimos, junto con 'anormalidad', 'rareza' y 'singularidad'; otros sinónimos consignados son exclusividad, originalidad y peculiaridad, entre varios más.

${ }^{2}$ Algunas obras recientes sobre historia prehispánica de México son: Linda Manzanilla y Leonardo López Luján (coords.), Historia Antigua de México, 1994-1995, México, Porrúa, 3 vols., y Lorenzo Ochoa (coord.), Gran historia de México ilustrada, 2001, México, Planeta, t. I.

${ }^{3}$ Un libro todavía muy utilizado y apreciado es el de George Vaillant, La civilización azteca, 1944, México, FCE. Un trabajo reciente es el de Eduardo Matos Moctezuma, Los aztecas, 2000, México, CONACULTA.

${ }^{4}$ Para un análisis comparativo entre aztecas e incas véanse los trabajos de Friedrich Katz, Ancient American Civilizations, 1972, Londres, Weidenfeld and Nicolson y "Mesoamérica y los Andes. Retrospectiva y comparación", en Nuevos ensayos mexicanos, 2006, México, Era, p. 13-28. 
bridores, y de los de la región andina del continente, que enfrentaron violentamente a sus conquistadores, los pueblos mesoamericanos llegaron a tener, después de una breve lucha armada, una coexistencia con los españoles considerablemente tranquila durante tres siglos. ${ }^{5}$ Para alcanzarse esta situación fue determinante el tipo de subordinación que muchos de estos pueblos sufrían respecto a los aztecas. De hecho, incluso colaboraron con los españoles en su guerra contra éstos, confiados en que su situación mejoraría con la derrota azteca. ${ }^{6} \mathrm{El}$ suyo era un dilema entre dos tipos de subordinación, y resolvieron elegir la menos dañina y la que incluyera el mayor número de beneficios. Con todo, de ninguna manera se pretende ignorar los graves y numerosos conflictos habidos entre nativos y españoles, conflictos que también se padecieron con criollos y mestizos: fueron encomendados y tuvieron que pagar tributos; cambiaron su régimen laboral y su cultura alimenticia; sus relaciones sociales fueron transformadas. Prueba de todo esto fue su desplome demográfico y el número de rebeliones armadas a lo largo del período. Si bien todo esto es innegable, puede sostenerse que entre los nativos mesoamericanos y los nuevos pobladores hubo una integración mucho mayor que en el resto del continente. ${ }^{7}$

Esta integración es la tercera 'particularidad' de la historia mexicana, y se le conoce como el mestizaje, proceso de mezcla racial y cultural que no se dio en el Caribe, donde hubo un rápido exterminio de la población original, ni en el resto del continente, donde prevaleció

${ }^{5}$ Un historiador tan perspicaz como documentado es Bernardo García Martínez, especialista en el período colonial, y en particular en los cambios sufridos por el sector indígena durante ese período. Véase su reciente colaboración en la Nueva historia mínima de México, México, El Colegio de México, p. 58-112.

${ }^{6}$ Las obras ‘clásicas' sobre la conquista son Hernán Cortés, Cartas de relación, 1960, estudio preliminar de Manuel Alcalá, México, Porrúa, Colección Sepan Cuantos, n 7; Bernal Díaz del Castillo, Historia verdadera de la conquista de la Nueva España: manuscrito Guatemala/Bernardo Díaz del Castillo, 2005, México-Madrid, El Colegio de México-UNAMServicio Alemán de Intercambio Académico-Agencia Española de Cooperación Internacional y William Prescott, Historia de la conquista de México, 1970, prólogo, notas y apéndices por Juan A. Ortega y Medina, México, Porrúa.

${ }^{7}$ Charles Gibson, Los aztecas bajo el domino español, 1519-1810, 1967, México, Siglo XXI. 
un permanente y mutuo rechazo. ${ }^{8}$ El mestizaje en México dio lugar a que surgiera una nueva raza y una nueva cultura: los españoles que se trasladaron a América cambiaron, transformación que palidece frente a la de los que ya nacieron en la nueva tierra, los llamados criollos. Durante los largos años de la coexistencia ${ }^{9}$ los indígenas también pasaron por profundos procesos de cambio. Obviamente, la mayor novedad consistía en la aparición de los mestizos, étnicamente más cercanos a los indígenas pero culturalmente más influidos por los españoles y los criollos. ${ }^{10}$

Aquella coexistencia entre conquistadores y nativos dio lugar a que un idioma, el español, y una religión, la católica, se consolidaran como mayoritarios en todo el territorio. Si bien fueron muchos los indígenas que por un largo tiempo permanecieron hablando en sus lenguas originales, fue creciente el número de los que se comunicaban en ambas; ${ }^{11}$ por su parte, los mestizos hablaron sólo en español. La hegemonía de la religión católica fue mayor que la del idioma español, ${ }^{12}$ aunque el catolicismo de aquí siempre fue distinto al que se practicaba en España, pues desde un principio se conservaron, así fuera clandestinamente, numerosas reminiscencias de las religiones de los nativos, lo que lo hacía una religión sincrética.

Cuarta 'particularidad': se instaló un aparato político-administrativo, el Virreinato de la Nueva España, con dimensiones únicas, que

${ }^{8}$ Consúltese Magnus Morner, Estado, raza y cambio social en la Hispanoamérica colonial, 1974, México, Secretaría de Educación Pública, Sep-Setentas, nº 128.

${ }^{9}$ En un estudio reciente se argumenta que hubo 'convivencia'. Véase Rodrigo Martínez Baracs, Convivencia y utopía. El gobierno indio y español de la "ciudad de Mechuacan", 1521-1580, 2005, México, CONACULTA-Instituto Nacional de Antropología e Historia-FCE.

${ }^{10}$ Luis González y González, Modales de la cultura nacional, en Obras, 2002, México, El Colegio Nacional, vol. VI, p. 7-193; mismo texto en Obras completas, 1995, México, Clío, vol. XIV.

${ }^{11}$ Véase Silvio Zavala, ¿El castellano, lengua obligatoria?, 1977, México, Centro de Estudios de Historia de México, CONDUMEX. Discurso de ingreso en la Academia Mexicana correspondiente de la Española, y respuesta del académico de número Manuel Alcalá Anaya.

${ }^{12}$ El rápido pero complejo proceso de imposición de la religión católica mereció que se le considerara una 'conquista espiritual'. Véase la obra, con ese título, de Robert Ricard, $L a$ conquista espiritual de México, 1947, México, JUs, trad. de Ángel María Garibay K. 
también colaboró, junto con la lengua y la religión, a la unificación de todos sus habitantes y elementos. ${ }^{13}$ Por lo mismo, puede decirse que a lo largo de los tres siglos coloniales se estuvo conformando en México una auténtica nación, en tanto que sus pobladores compartían lengua, religión, cultura, organización política y hasta una joven historia. ${ }^{14}$ Acaso ésta sea una de las principales 'particularidades' de la historia mexicana: su proceso de construcción de una nación estaba considerablemente maduro al principiar el siglo XIX.

La naciente nación todavía no era un país. El proceso independentista dio lugar a que esa nación construyera posteriormente un Estado nacional. Por obvias razones geográficas y sociodemográficas la lucha independentista tuvo en México 'particularidades' notables, las que pueden ser agrupadas como la quinta. La más importante fue la nutrida participación de los mestizos, quienes a su vez sirvieron para movilizar a algunos contingentes indígenas. Por esto tuvo un carácter más popular que en el resto de los procesos independentistas americanos. ${ }^{15}$ Asimismo, la independencia mexicana fue un proceso aislado, a diferencia de las sudamericanas, que fueron un proceso compartido, casi común. Finalmente, y como prueba de su mayor madurez como nación, la independencia mexicana dio lugar a un país que buscaba más su pasado como nación que su futuro como joven Estado. ${ }^{16}$

Otra 'particularidad'-la sexta-es que México, al independizarse, heredó del Virreinato de la Nueva España una más definida unidad

${ }^{13}$ Consúltese José Miranda, Las ideas y las instituciones politicas mexicanas, 1952, México, UNAM.

${ }^{14}$ Consúltese Jaime E. Rodríguez y Colin M. Mac Lachlan, Hacia el ser histórico de México: una reinterpretación de la Nueva España, 2001, México, Diana.

${ }^{15}$ Véase Jonh Lynch, Las revoluciones hispanoamericanas, 1808-1826, 1976, Barcelona, Ariel. Para una visión más actualizada, que contemple los procesos político-constitucionales, esto es, no sólo la lucha por romper con España sino también la creación simultánea de los nuevos países, véase Jaime E. Rodríguez O., La independencia de la América española, 2005, México, El Colegio de México-Fideicomiso Historia de las Américas-FCE.

${ }^{16}$ A diferencia de otros países que vincularon su nombre a alguno de los líderes de la guerra de independencia, el de México hace referencia a los principales pobladores originales. Cfr. Gutierre Tibón, Historia del nombre y de la fundación de México, 1975, México, FCE. 
político-administrativa. Los estados que conformaron la república federal mexicana provenían de las Intendencias borbónicas, y éstas a su vez de los reinos y capitanías habsburgas. Asimismo, el joven México correspondió casi idénticamente al Virreinato de la Nueva España. ${ }^{17}$ En cambio, en sudamérica los virreinatos fueron divididos para constituir varios países. Esta diferencia evitó a México, salvo por los que se tuvieron con Guatemala, numerosos problemas en cuanto a la definición de sus límites y fronteras.

Al México del siglo XIX también lo caracterizaron otras 'particularidades': padeció, como todos los países recién independizados, la falta de un gobierno central eficiente y estable, la proliferación de caciques y caudillos y la falta de cultura e instituciones políticas, lo que ocasionó que la competencia por el poder se diera mediante procedimientos castrenses; también padeció, como los otros países hispanoamericanos, la pobreza de su economía. Sin embargo, fue único -séptima 'particularidad'-en cuanto al peso y número de los mestizos que participaron en la política, sobre todo durante la segunda mitad del siglo. ${ }^{18}$

La siguiente 'particularidad' decisiva -la octava- consiste en tener una enorme frontera con los Estados Unidos, pues es el único país hispanoamericano que colinda con una potencia con grandes pretensiones territoriales, otra lengua, otra religión y otra raza. De

${ }^{17}$ Consúltese Edmundo O'Gorman, Breve historia de las divisiones territoriales: aportación a la historia de la geografía de México, 1937, México, Polis.

${ }^{18}$ La historiografía de finales del siglo XIX y principios del XX estaba muy influida por las interpretaciones etnicistas y raciales, por lo que destacó el creciente papel de los mestizos en la vida nacional. Véanse Justo Sierra, México, su evolución social, 1900, México, J. Ballescá; Andrés Molina Enríquez, Los grandes problemas nacionales, 1909, México, Imprenta de A. Carranza e Hijos y Emilio Rabasa, La Evolución Histórica de México, 1920, México, Librería de la Vda., De Ch. Bouret. Aunque su visión del mestizaje está ya más influida por el vitalismo, véase José Vasconcelos, "El evangelio del mestizo", introducción, traducción y notas de Luis Barrón, en Istor. Revista de historia internacional, verano de 2006, México, Centro de Investigación y Docencia Económicas, año VII, $\mathrm{n}^{\circ} 25$, p. 80-98. Para una visión comparativa con el mestizaje de la vecina Guatemala, véase Mauricio Tenorio Trillo, "Guatemala y México: del mestizaje a contrapelo", en Istor. Revista de historia internacional, primavera de 2006, México, Centro de Investigación y Docencia Económicas, año VI, n² 24, p. 67-94. 
hecho, además de un intento de reconquista española -en 1829- y de sufrir la escisión de Texas en 1836, a mediados del siglo xIx, y luego de una guerra breve y desigual, Estados Unidos se apropió de la mitad del territorio original del país. ${ }^{19}$ Seguramente esto explica que desde entonces predomine en México una ideología nacionalista, la que más bien debería considerarse yancofóbica, pues luego de aquella gran pérdida de territorio era comprensible que se temiera que México pudiera desaparecer como nación, absorbido por los estadounidenses. Esta ideología nacionalista -explícita en la composición del 'himno nacional' en 1854-, ${ }^{20}$ se exacerbó luego de haber resistido y vencido a una grave intervención francesa a mediados del decenio de los 60', intervención que dio lugar a que México llegara a ser gobernado por un miembro de la dinastía reinante en el Imperio Austro Húngaro. ${ }^{21}$ Ningún otro país del continente ha padecido una intervención similar en magnitud y duración. Esta sería nuestra novena 'particularidad', provocada en cierto sentido por su 'particularidad' geográfica, pues Europa deseaba construir en México un dique a la expansión estadounidense y un puente comercial con Asia.

Paradójicamente, el haber enfrentado estas dos guerras internacionales no se tradujo en el fortalecimiento del ejército profesional central, ni dio lugar a que la ideología nacionalista del país se definiera

${ }^{19}$ Para conocer la historia de los conflictos internacionales de México, véase México y el mundo: historia de sus relaciones exteriores, 1990, México, Senado de la República, en particular los t. II y III. Véase también Josefina Vázquez y Lorenzo Meyer, México frente a Estados Unidos: un ensayo histórico, 1776-1980, 1982, México, El Colegio de México. Una visión moderna, de la que se puede concluir que el costosísimo resultado de aquella guerra obligó a la integración del país, en Josefina Vázquez, (coordinación e introducción), México al tiempo de su guerra con Estados Unidos, 1846-1848, 1997, México, Secretaría de Relaciones Exteriores-El Colegio de México-FCE.

${ }^{20}$ La bandera nacional había sido definida desde 1824, e incluía un 'escudo' de enorme significación simbólica, el que rescataba la versión sobre la fundación de México que aparece en varios códices indígenas. Véase Enrique Florescano, La bandera mexicana: breve historia de su formación y simbolismo, 2000, México, Taurus. Respecto al himno, véase Vicente Quirarte y Clementina Díaz y de Ovando, El Himno Nacional Mexicano, 2004, México, Archivo General de la Nación-Secretaría de Gobernación.

${ }^{21}$ Véase Erika Pani, Para mexicanizar el segundo imperio: el imaginario político de los imperialistas, México, 2001, El Colegio de México-Instituto Mora. 
desde la corporación castrense. Esto se debió a que era tal el poderío de Estados Unidos, que para contrarrestarlo no hubiera sido suficiente destinar todos los ingresos del país al presupuesto militar. Además, el ejército central profesional no había combatido a la intervención francesa; todo lo contrario, la había apoyado en tanto que el enemigo común eran los liberales, cuyos ejércitos estaban más vinculados a la sociedad civil y a los poderes regionales. En consecuencia, a mediados del XIX se construyó en México un ejército de dimensión moderada y de ideología liberal, más vinculado a los mestizos que a los criollos, quienes habían dominado y lucrado con el ejército postindependentista. El triunfo de las fuerzas liberales a mediados del siglo xIX, mediante tres largas campañas militares -Ayutla, 'Tres Años' e Intervención-, dio lugar a que el ejército que desde la consumación de la Independencia había mantenido el poder, con Antonio López de Santa Anna y Anastasio Bustamante al frente de una oficialidad criolla, fuera relevado como la principal institución política y militar del país por un ejército dominado por mestizos como Porfirio Díaz.

A diferencia de México, en la mayoría de los países sudamericanos los ejércitos siguieron encabezados por elementos criollos tendientes a constituirse o a vincularse con las oligarquías locales. Esta -novena'particularidad' permitió a México distinguirse de la mayoría de los otros países latinoamericanos, con problemas fronterizos con vecinos de fuerzas muy equilibradas, condición que dio lugar a la construcción de ejércitos nacionales poderosos, encabezados por militares con una ideología nacionalista motivada por la defensa territorial. ${ }^{22}$

${ }^{22}$ Un estudio breve pero general de la historia latinoamericana, ya clásico, es el de Tulio Halperin Donghi, Historia contemporánea de América Latina, 1987, México, Alianza. Para una visión más amplia véase Leslie Bethell (ed.), Historia de América Latina, 1997, Barcelona, Crítica-Grijalbo Mondadori, 16 vols. Véase también Historia general de América Latina, 1999, Madrid-París, Trotta Ediciones-UNESCO, 6 vols., a la fecha. Para el tema del militarismo véase Edwin Lieuwen, Armas y política en América Latina, 1960, Argentina, SUR. Para un análisis sobre Argentina, consúltese Ricardo Forte, Fuerzas armadas, cultura política y seguridad interna: orígenes y consolidación del poder militar en Argentina, 18531943, 2001, México, R. Fonte, (tesis de doctorado en historia). 
Siguiendo con esta enumeración, la décima 'particularidad' mexicana consiste en la enorme fuerza de la Iglesia católica. Dado que para ésta la conquista de América significaba la posibilidad y la responsabilidad de cristianizar a los habitantes de las nuevas tierras, el número de fundaciones y de miembros de las órdenes religiosas que se asentaron en cada región del continente dependió de su densidad poblacional. Si a los cálculos hechos por la historia demográfica los caracteriza su variabilidad, al menos coinciden en que para el período prehispánico la región más densamente poblada era mesoamérica. ${ }^{23}$ Por lo mismo, la Iglesia tuvo que tener en la parte mexicana del continente mucho mayor presencia que en las zonas caribeña y meridional. ${ }^{24}$

La Iglesia católica llegó a ser una institución con una estructura que abarcaba el territorio por entero, con influencia en todas las clases sociales y en todos los ámbitos: cultural, económico, político y social, además del religioso. Comprensiblemente, al resquebrajarse y transformarse el aparato político-administrativo colonial a causa de la Independencia, la Iglesia católica quedó como la única estructura que realizaba a nivel nacional funciones propias de un Estado: educaba, cobraba impuestos, llevaba estadísticas, controlaba las relaciones civiles y hasta cohesionaba a la nación, a través del mito y símbolo de la Virgen de Guadalupe. ${ }^{25}$ Es un hecho que el poderío de la Iglesia católica se había reducido durante la Ilustración y con la llegada al poder en España de la dinastía borbónica. A pesar de tal declive, al crearse un Estado nacional moderno la Iglesia resultó un obstáculo, y como competidor tuvo que ser desplazada, disminuida y acotada. Este conflicto tuvo lugar a mediados del siglo XIX y se le conoce como la guerra

${ }^{23}$ Sherburne Cook y Woodrow Borah, Ensayos sobre historia de la población: México y el Caribe, 1977-1980, México, Siglo Veintiuno Editores, 3 vols. Para el México central arriesgan una cifra de 25 millones en la víspera de la conquista. Cfr., vol. I, p. 11.

${ }^{24}$ La Nueva España fue la región con mayor presencia de órdenes religiosas, la que tuvo a su vez su propia distribución geográfica. Cfr. Elena Vázquez, Distribución geográfica y organización de las órdenes religiosas en la Nueva España: siglo XVI, México, UNAM, 1965.

${ }^{25}$ Jacques Lafaye, Quetzalcóatl y Guadalupe: la formación de la conciencia nacional en México, 1977, México, FCE y David Brading A., La Virgen de Guadalupe: imagen y tradición, 2002, México, Taurus. 
de Reforma, entre liberales y conservadores. Aunque hubo conflictos similares en otros países, la magnitud del mexicano fue única, ${ }^{26}$ como consecuencia del tamaño y fuerza de su Iglesia. Una secuela importante -y undécima 'particularidad'- es que en México se desarrollaron en forma antagónica el ejército y la Iglesia, instituciones que en otros países latinoamericanos han compartido posiciones y objetivos.

En términos generales, el liberalismo surgió en Europa cuando las emergentes clases medias se opusieron a la política absolutista de las monarquías y a los privilegios de la aristocracia. En México el proceso fue radicalmente distinto, pues en el siglo XIX, por su naciente tradición republicana, ya no había una monarquía encabezando un Estado absolutista. De hecho, en México aún no se consolidaba el Estado. Así, en lugar de que las clases medias lucharan contra la aristocracia ${ }^{27}$ o para reducir un poder absoluto, ambos inexistentes, se esforzaron en construir un aparato estatal propio, que encabezara la defensa del país y ayudara a mejorar la organización de la sociedad. Cierto es que las constituciones de 1824 y 1857 estaban diseñadas para contrarrestar los modelos gubernamentales autoritarios de Agustín de Iturbide y Antonio López de Santa Anna, pero también es cierto que más que contra una fuerte monarquía o contra una aristocracia omnipresente, las clases medias mexicanas se enfrentaron a la Iglesia católica, en tanto que cumplía funciones estatales. La siguiente 'particularidad'-duodécima- consiste en que el liberalismo mexicano tuvo - y tiene- dos características. Por un lado, fue más jacobino que democrático. Por el otro, dado que desde principios de los tiempos coloniales la Iglesia había asumido responsabilidades propiamente gubernamentales, al

${ }^{26}$ Consúltese México a través de los siglos, Tomo V. La Reforma, de José María Vigil, México, Ballescá Editores, s/a, y Manuel Rivera Cambas, Historia de la Intervención Europea y Norteamericana en México y del Imperio de Maximiliano de Habsburgo, 1888, México, Tipografía de Aguilar é hijos, 3 tomos.

${ }^{27}$ Algunos autores sostienen que los hacendados porfiristas equivalían a nuestra aristocracia, y que por eso la Revolución mexicana fue una lucha liberal y 'burguesa'. Cfr., Alan Knight, “La Revolución mexicana: ¿burguesa, nacionalista, o simplemente una ‘gran rebelión’?”, en Cuadernos Políticos, México, Era, n 48, octubre-diciembre de 1986, p.5-32. 
reducir a la Iglesia el Estado creado por los liberales tuvo que asumir dichas labores. Así se explica que acaso sea México el país del continente con la Iglesia más fuerte y con la sociedad más católica, pero con el aparato gubernamental y las disposiciones legislativas con más elementos jacobinos. ${ }^{28}$ Asimismo, el liberalismo mexicano incluso resultó estatista, ${ }^{29}$ condición que fue reforzada durante la Revolución, haciendo de México - junto con Cuba- el país más estatista del continente. ${ }^{30}$

En el tránsito de los siglos XIX a XX México presentó una notable 'particularidad' -la décimotercera-la que podría ser considerada sociohistórica, consistente en una muy singular combinación de factores políticos, sociales y económicos. Sucedió que México fue el único país latinoamericano donde coexistieron una dictadura, el latifundismo y un gran crecimiento económico. Varios países andinos y centroamericanos -léase Guatemala, Perú y Bolivia, entre otros- padecieron una prolongada dictadura y una muy injusta distribución de la propiedad de la tierra. Lo mismo pasó en México, pero en éste, a diferencia de los anteriores, hubo un gran crecimiento económico, con el consiguiente desarrollo de clases sociales modernas, como el proletariado y los sectores urbanos medios. Mientras que en los primeros países los enconos en el mundo rural estaban condenados a expresarse, cuando mucho, como rebeliones campesinas, en México existía la posibilidad de alianzas pluriclasistas.

${ }^{28}$ En este tema la historiografía mexicana ha asumido una posición radical y contrapuesta, siempre a partir del bando ideológico del autor. Los ministros del culto católico metidos a historiadores siempre escribieron páginas condenatorias del bando liberal, mientras que los políticos e ideólogos liberales que escribieron sobre historia lo hicieron desde una perspectiva jacobina. Afortunada y recientemente, historiadores profesionales han producido textos desde una perspectiva más neutral y científica.

${ }^{29}$ La visión más acorde con este liberalismo es la de Jesús Reyes Heroles, El liberalismo mexicano, 1957-1961, México, UNAM, 3 vols.

${ }^{30}$ Incluso durante los últimos veinte años, cuando los gobernantes mexicanos impusieron políticas económicas llamadas 'neoliberales', se ha mantenido una política asistencial considerable, en tanto que es un compromiso histórico del Estado mexicano. 
De otra parte, ese crecimiento económico y ese desarrollo social también se dieron en países del cono sur como Argentina, Chile y Uruguay. Sin embargo, en éstos no había dictaduras; al contrario, había instituciones y procesos políticos -léase auténticos poderes legislativos y sindicatos- por los que se canalizaron y expresaron las demandas y posturas políticas de las clases medias y del proletariado; en consecuencia, ambos sectores fortalecieron a sus respectivos sistemas políticos. En México, dado que no había tales instituciones políticas, las clases medias y los trabajadores no se vieron representados debidamente y terminaron por ser elementos desestabilizadores. En resumen, sólo en México se dio esa muy 'particular' combinación, por la que se aliaron clase media, proletariado y comunidades campesinas, sin lugar a dudas las más fuertes del continente. ${ }^{31}$ El resultado de esa combinación dio lugar a la Revolución mexicana, otra gran 'particularidad'.

La Revolución fue la mayor 'particularidad' mexicana del siglo $\mathrm{XX}, \mathrm{y}$ trajo varias secuelas, como la definición de un nuevo proyecto de desarrollo histórico nacional; una mayor integración de casi todos los habitantes del país; la construcción de un gran aparato gubernativo; la modernización de su sociedad y de su economía, y la invención de una cultura nacional y nacionalista. Entre sus secuelas negativas, la Revolución hizo que un grupo alcanzara el poder mediante el triunfo armado, con un alto gasto de sangre, lo que dio lugar a la conformación de un aparato político-militar autoritario, encabezado por un grupo decidido a no compartir, y mucho menos a entregar, dicho poder.

$\mathrm{Si}$ bien es cierto que las revoluciones dividen y que las guerras internacionales unifican, la Revolución mexicana tuvo varios ingredientes internacionales, ${ }^{32}$ lo que le permitió ser más un proceso cohesionador que divisivo. Puede asegurarse que una 'particularidad' genera otras, y luego éstas otras, y así sucesivamente. En este caso,

${ }^{31}$ En este, como en tantos otros temas, reconozco mi deuda intelectual con mi maestro Friedrich Katz.

${ }^{32}$ Además de las amenazas y presiones permanentes del gobierno norteamericano, destacan la invasión a Veracruz, en 1914, y la ‘Expedición Punitiva', durante 1916. 
la Revolución dio lugar a una notable paradoja histórica: el país que padeció la más grave y prolongada -1910 a 1930- dosis de violencia, ha sido luego el país latinoamericano con mayor estabilidad política: desde 1934 todos sus presidentes han terminado en tiempo y forma el período para el que habían sido electos. ${ }^{33}$ Asimismo, la Revolución acentuó el carácter popular y antioligárquico del ejército mexicano, lo que explica que desde 1930 éste no haya estado involucrado en cuartelazo o rebelión alguna. La legitimidad y la estabilidad del Estado mexicano posrevolucionario resultan balanceadas por la falta de democracia.

La ausencia de dictaduras es otra 'particularidad' notable, la que acaso pueda ser explicada por varios factores: el primero, la Revolución fue hecha, al menos discursivamente, para erradicar las dictaduras de nuestra historia; después, la eficacia del PRI en la consecución de un prolongado orden social, lo que redujo el número de reclamos; por último, el carácter popular y progresista del ejército mexicano.

En síntesis, la historia mexicana resulta ser un proceso caracterizado por la multiplicación de 'particularidades'. Las más importantes son su 'particularidad' geográfica, señaladamente la frontera con Estados Unidos; su 'particularidad' racial, basada en el mestizaje; sus 'particularidades' bélicas, como lo fueron las guerras con Estados Unidos y con Francia en el siglo XIX, y las luchas revolucionarias del XX; su 'particularidad' social, como lo fue la falta de inmigración europea a finales del siglo XIX y principios del XX; su 'particularidad' cultural, pues la fuerza de la religión católica ha dado lugar a que los sectores conservadores mexicanos sean tan nacionalistas, en su vertiente yancófoba, como los progresistas. ${ }^{34}$ En efecto, el catolicismo mexicano es

${ }^{33}$ Consúltese Luis Medina Peña, Hacia el nuevo estado: México, 1920-1994, 1994, México, FCE. Recientemente el mismo autor publicó un libro igualmente útil e interesante, dedicado al análisis del siglo anterior, titulado Invención del sistema político mexicano: forma de gobierno y gobernabilidad en México en el siglo XIX, 2004, México, FCE.

${ }^{34}$ Véase el artículo de Jaime del Arenal, "El nacionalismo conservador mexicano del siglo XX", en las p. 329-354 del libro editado por Cecilia Noriega Elío, El nacionalismo en México, 1992, México, El Colegio de Michoacán. 
nacionalista, y lo ha sido desde el nacimiento del país, cuando en la guerra de Independencia participaron, con el mayor protagonismo, cerca de 400 sacerdotes. ${ }^{35}$ Justifica la Iglesia su oposición al desarrollo del protestantismo en el país en que atenta contra la identidad nacional, lo que la lleva a su radical crítica de la sociedad y la cultura estadounidenses. La diferencia esencial del nacionalismo conservador y católico mexicano respecto del llamado nacionalismo progresista consiste en que el primero es, comprensiblemente, decididamente antiestatista y antiliberal. Asimismo, otra 'particularidad' consiste en la existencia en México de un nacionalismo progresista, de 'izquierda', tanto social como gubernamental.

Podría continuarse con la enumeración de otras 'particularidades', como una de carácter geológico, consistente en la existencia de grandes mantos petrolíferos, condición sólo compartida con Venezuela. Sin embargo, acaso sea mejor concluir señalando que México tiene tanto elementos comunes como diferencias con los otros países latinoamericanos. Por ejemplo, padeció un dominio colonial que se prolongó por tres siglos; comparte lenguaje y religión; nacieron como países simultáneamente, y todos optaron por la forma republicana de gobierno; como los otros países latinoamericanos, México padece dependencia económica y atraso social en buena parte de su población. También podría hacerse un recuento de varios elementos comunes. Incluso podría preguntarse sobre lo que predomina en la historia de México: ¿'particularidades' o semejanzas? Seguramente debe responderse que la historia de México, como la de cualquier otro país, consiste en la siempre creciente acumulación de 'simpatías y diferencias'.

${ }^{35}$ José María Miquel i Verges, Diccionario de insurgentes, 1969, México, Porrúa. Para evitar generalizaciones equívocas, debe subrayarse que, a diferencia de lo sucedido en la lucha independentista y en la guerra contra Estados Unidos de 1846-1848, cuando grandes sectores eclesiásticos participaron a favor de la causa nacional, durante la Intervención francesa la Iglesia católica mexicana luchó junto con los invasores contra el gobierno liberal mexicano. Para un análisis del patriotismo católico mexicano, véase Jean Meyer, "Religión y nacionalismo", p. 703-18 de la obra editada por Cecilia Noriega Elío citada en la nota anterior. 